\title{
THE MODELING AND ANALYSIS OF A POWER TRANSMISSION LINE SUPPLIED BY A SOLAR POWER PLANT
}

\author{
Erol CAN
}

\begin{abstract}
This article deals with the energy transmission line system which feeds from solar energy at the MATLAB Simulink. So, direct voltage is considered to be converted as an alternating voltage by a 35-level inverter after the solar power plant which has the power of $110 \mathrm{MW}$ produce $360 \mathrm{kV}$ of direct voltage. A line which covers $240 \mathrm{~km}$ of distance is preferred to transmit electrical power from the A1 point to an A2 point. Due to this, the required mathematical equations are calculated with a circuit analyzing method for the line modeling in the simulation. Experiments on the model are carried out at the MATLAB Simulink after the creation of an energy transmission line. After that, when measurements are made taking into consideration the A2 node; the capacitor voltage, the transformer current, the A2 node current, and the fault current, values are given according to the converted voltage at the frequencies of $100 \mathrm{~Hz}, 80 \mathrm{~Hz}$, and $50 \mathrm{~Hz}$. The obtained results demonstrate the success of the proposed line system, while power is distributed with eliminated fault at a long distance at different frequencies.
\end{abstract}

Keywords: mathematical model of the line; simulation model of the transmission line; 35-level inverter

\section{INTRODUCTION}

Solar power is widely considered and used in many studies $[1,2]$. However, solar energy usually needs long-line transmission because most solar centers are far away from the users, i.e. consumers. The processes of series compensation are considered at long distance transmission for improving the situation of the power line [3-5]. In this research, the energy power line to be compensated is fed with a correct voltage of $360 \mathrm{kV}$ provided by a solar power plant with the power of $110 \mathrm{MW}$. This voltage value can be obtained by a serial connection of the voltage generated by a large number of inverters, although this is not necessary in the simulation operation. The operation of the inverter for solar-powered systems is widespread [6-8], but at the usage of the inverter for the power transmission line, it is difficult to achieve good performance because the alternating voltages that an inverter produces can have a high harmonic distortion. Therefore, it is necessary to use an inverter with a much higher level than the multi-level inverters used up to now. For this reason, unlike in other studies [8-10], the 35-level inverter is used to invert the direct voltage of a solar power plant to an alternating voltage for the power line. Additionally, although inverter applications are circuits for energy conversion and control of electrical machines [12-14], the study is different from other studies because of a solar power plant with a 35-level inverter which feeds an energy transmission line. A solar-powered transmission line covering a long distance is difficult and time-consuming and expensive to test and measure when the line transmits energy and has faults. Therefore, the modeling and simulation of the line are important and necessary applications. The mains frequencies can change from country to country at the same time. So, It is important that the energy transmission line operated by producing voltage with different frequencies from a solar center, including the low-level distortion of the voltage. Thus, after the proposed system has been established, the system is simulated on a power line of 240 $\mathrm{km}$ that is fed by alternating voltage at the frequency of 80 $\mathrm{Hz}$. When the simulation is performed, the parallel switch in Fig. 2 for the fault generation at the line is activated from time to time and a fault is generated on the line. Then, the fault current, the flux, and the magnetizing current of the transformer are observed with a multimeter block. The capacitor voltage, the MOV current and the flux of the A2 point are measured by a scope1. According to the obtained results for alternating voltage at $80 \mathrm{~Hz}$, parallel resonances correspond to the $10 \mathrm{~Hz}$ and $110 \mathrm{~Hz}$ modes. The $10 \mathrm{~Hz}$ mode is due to a parallel resonance of the series capacitance and the shunt reactance of the line. The $110 \mathrm{~Hz}$ mode occurs due to the resonance effect of the shunt line capacitance and the series reactance of the transmission system. By using these two modes, faults can be eliminated. According to the obtained results for alternating voltage at $50 \mathrm{~Hz}$, parallel resonances correspond to the $5 \mathrm{~Hz}$ and $85 \mathrm{~Hz}$ modes. The 5 $\mathrm{Hz}$ mode is due to a parallel resonance of the series capacitance and the shunt reactance of the line. The $85 \mathrm{~Hz}$ mode occurs due to the resonance effect of the shunt line capacitance and the series reactance of the transmission system. By using these two modes, faults can be eliminated while the inverter is producing alternating voltage at $50 \mathrm{~Hz}$. Therefore, some contributions were made as a result. The power line has been tried with switching inverters in the frequency range of $50-100 \mathrm{~Hz}$ since the mains frequency can vary from country to country. Direct voltage obtained from the solar power plant was transferred to alternating voltage at different frequencies. It was seen that different countries could adapt this model to the power lines because the energy at different frequencies has been successfully transmitted while eliminating faults through the power line. Distortion values on generated voltage from DC voltage in this research were quite acceptable, while the distortion of generated voltage from direct voltage was very high and unacceptable in other studies $[15,16]$. Additionally, the distortion of alternating voltage feeding the inspected power line in the open loop control is below $5 \%$, which is the 
acceptable level, while the distortion in the producing of DC power in some open loop control operations exceeds $5 \%$ in the power system studies [17, 18]. Although it is a difficult, expensive and time-consuming process to work on long lines, this simulated model with MATLAB Simulink measured the response of a solar-powered line in a short time and at a low cost.

\section{POWER LINE DESIGN}

In the design of electric power lines, which is powered by a solar power plant of $110 \mathrm{MW}$, is compensated at the center of the line by a capacitor representing $30 \%$ of line reactance for raising the transmission capability at the center of the line. The line is also shunt compensated at both ends by a $165 \mathrm{MVAr}$ shunt reactance (55 MVAr/phase). A metal oxide varistor $(\mathrm{MOV})$ protects the series capacitor from the line. The 110 MVA, $360 \mathrm{kV} / 180 \mathrm{kV}$ transformer is connected as a saturable transformer simulation block for the other end of the power line. According to the mentioned, an equivalent circuit model of the line in Fig. 1 is created and the required mathematical equations for modeling are formed with a circuit analysis method.

\subsection{Equivalent Circuit Model}

The power line to be modeled in MATLAB Simulink is similar to the equivalent circuit of the analysis in Fig. 1. A big solar power plant can be created with multiple solar batteries assembling in one roof connected to a common collecting point. In Fig. 1, the electrical voltage generated by this solar energy is represented as $V_{\mathrm{S}}$ on the circuit model. $R_{\mathrm{S}}$ is the resistance of the transmission line; $Z_{\mathrm{S}}$ is the shunt impedance $\left(R_{\mathrm{S}}, L_{\mathrm{S}}, C_{\mathrm{S}}\right)$ of the transmission line. The impedance mathematical values are listed as Eq. (1) and Eq. (2). $\omega$ is the angular frequency, $\omega=2 \pi f$.

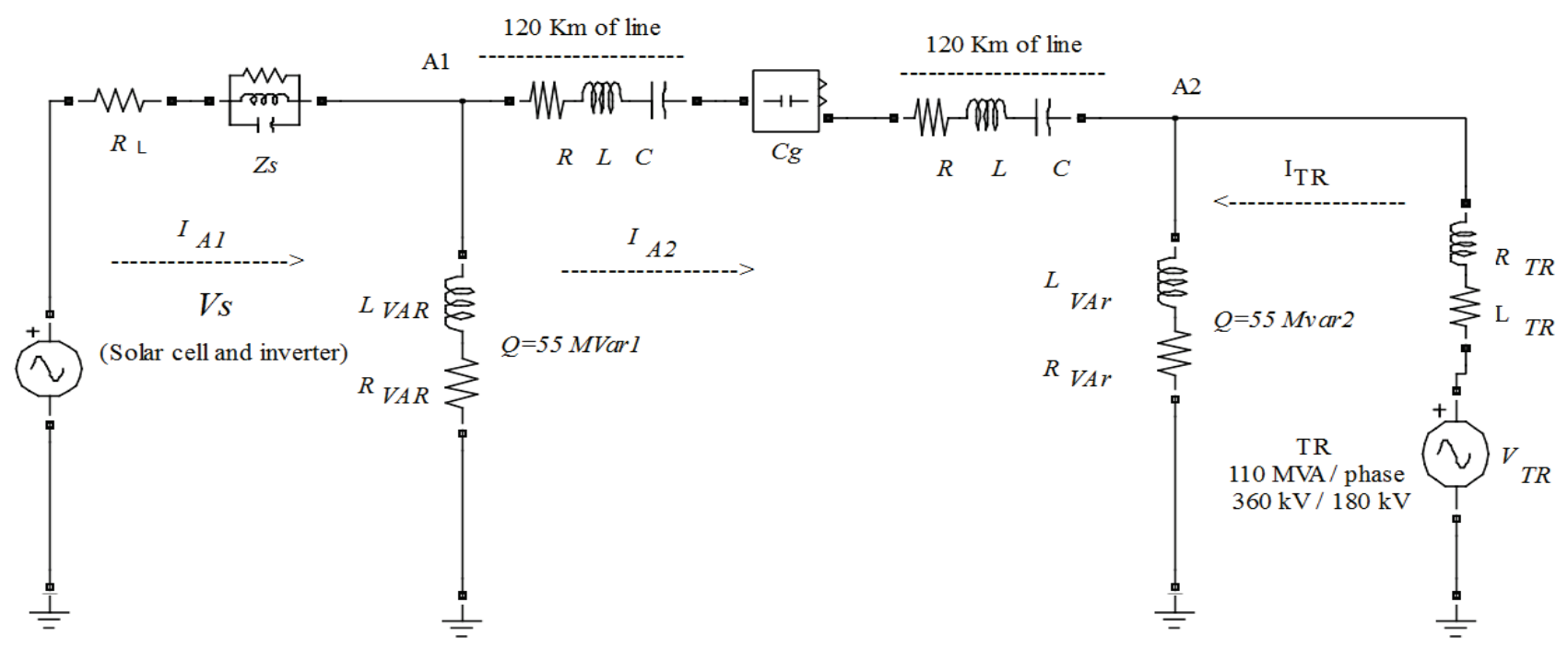

Figure 1 Equivalent circuit of the compensated line for modeling

$\frac{1}{Z_{\mathrm{S}}}=\frac{1}{R_{\mathrm{S}}}+\frac{1}{j \omega L_{\mathrm{S}}}+\frac{1}{1 / j \omega C_{\mathrm{S}}}$

$$
\left[\begin{array}{c}
\frac{1}{Z_{\mathrm{S}}}=\frac{j \omega L_{\mathrm{S}}+R_{\mathrm{S}}}{j \omega L_{\mathrm{S}} \cdot R_{\mathrm{S}}}+j \omega C_{\mathrm{S}} \\
\frac{1}{Z_{\mathrm{S}}}=\frac{1}{\frac{j \omega L_{\mathrm{S}}+R_{\mathrm{S}}}{j \omega L_{\mathrm{S}} \cdot R_{\mathrm{S}}}+j \omega C_{\mathrm{S}}} \\
Z_{\mathrm{S}}=\frac{j \omega L_{\mathrm{S}} \cdot R_{\mathrm{S}}}{j \omega L_{\mathrm{S}}+R_{\mathrm{S}}-\omega^{2} L_{\mathrm{S}} C_{\mathrm{S}} R_{\mathrm{S}}}
\end{array}\right]
$$

$V_{\mathrm{S}}$ represents the voltage obtained by the inverter from the solar power plant, $Z_{\mathrm{VAr}}$ represents the parallel impedances forming the reactive power on the line for the line to be modeled. Eq. (3) shows the mathematical equality for $Z_{\mathrm{VAr}}$.

$$
Z_{\mathrm{VAr}}=j \omega L_{\mathrm{VAr}}+R_{\mathrm{VAr}}
$$

For creating the $240 \mathrm{~km}$ of line, two equal $R L C$ series are added to the line. In the simulation model, $Z_{\mathrm{w}}$ is the load impedance representing the $240 \mathrm{~km}$ of line. Eq. (4) shows the mathematical equality for $\mathrm{Z}_{\mathrm{w}}$

$Z_{\mathrm{W}}=j \omega L+R+\frac{1}{j \omega C}$

$Z_{\mathrm{A} 1}$ represents the impedance of the first part of the circuit section with respect to the A1 point. Eq. (5) and Eq. (6) give the mathematical equality of $Z_{\mathrm{A} 1}$.

$Z_{\mathrm{A} 1}=j \omega L_{\mathrm{VAr}}+R_{\mathrm{VAr}}+R_{\mathrm{L}}+\frac{j \omega L_{\mathrm{S}} \cdot R_{\mathrm{S}}}{j \omega L_{\mathrm{S}}+R_{\mathrm{S}}-\omega^{2} L_{\mathrm{S}} C_{\mathrm{S}} R_{\mathrm{S}}}$ 


$$
Z_{\mathrm{A} 1}=Z_{\mathrm{S}}+Z_{\mathrm{VAr}}+R_{\mathrm{L}}
$$

According to A1 point, the surrounding current equation of the first section can be written as Eq. (7) and Eq. (8). $I_{\mathrm{A} 1}$ is first section current and $I_{\mathrm{A} 2}$ is second section current.

$$
\begin{aligned}
& V_{\mathrm{S}}=I_{\mathrm{A} 1}\left(j \omega L_{\mathrm{VAr}}+R_{\mathrm{VAr}}+R_{\mathrm{L}}+\frac{j \omega L_{\mathrm{S}} \cdot R_{\mathrm{S}}}{j \omega L_{\mathrm{S}}+R_{\mathrm{S}}-\omega^{2} L_{\mathrm{S}} C_{\mathrm{S}} R_{\mathrm{S}}}\right)- \\
& -\left(j \omega L_{\mathrm{VAr}}+R_{\mathrm{VAr}}\right) I_{\mathrm{A} 2} \\
& V_{\mathrm{S}}=I_{\mathrm{A} 1}\left(Z_{\mathrm{S}}+Z_{\mathrm{VAr}}+R_{\mathrm{L}}\right)-\left(Z_{\mathrm{VAr}}\right) I_{A 2}
\end{aligned}
$$

According to A2 point, the surrounding current equations for the line between the $\mathrm{A} 1$ and $\mathrm{A} 2$ points are found for the simulation model after the first line section of the surrounding current equation is formed. $C_{\mathrm{g}}$ is the seriescompensated capacitance for the line. Since there is no source for the second partition, the equation is listed as Eq. (9), Eq. (10) and Eq. (11). $I_{\mathrm{TR}}$ is the third section current.

$$
\begin{aligned}
& 0=I_{\mathrm{A} 2}\left(2 j \omega L_{\mathrm{VAr}}+2 R_{\mathrm{VAr}}+2 j \omega L+2 R+2 \frac{1}{j \omega C}+\frac{1}{j \omega C_{\mathrm{g}}}\right)- \\
& -\left(j \omega L_{\mathrm{VAr}}+R_{\mathrm{VAr}}\right) I_{\mathrm{A} 1}+\left(j \omega L_{\mathrm{VAr}}+R_{\mathrm{VAr}}\right) I_{\mathrm{TR}}
\end{aligned}
$$

$$
\left[\begin{array}{cc}
\left(j \omega L_{\mathrm{VAr}}+R_{\mathrm{VAr}}+R_{\mathrm{L}}+\frac{j \omega L_{\mathrm{S}} \cdot R_{\mathrm{S}}}{j \omega L_{\mathrm{S}}+R_{\mathrm{S}}-\omega^{2} L_{\mathrm{S}} C_{\mathrm{S}} R_{\mathrm{S}}}\right) & \left(j \omega L_{\mathrm{VAr}}+R_{\mathrm{VAr}}\right) \\
-\left(j \omega L_{\mathrm{VAr}}+R_{\mathrm{VAr}}\right) & {\left[\begin{array}{c}
\left.2 j \omega\left(L_{\mathrm{VAr}}+L\right)+2\left(R_{\mathrm{VAr}}+R\right)+\frac{1}{j \omega}\left(2 \frac{1}{C}+\frac{1}{C_{\mathrm{g}}}\right)\right] \\
0 \\
\left(j \omega L_{\mathrm{TR}}+R_{\mathrm{TR}}\right)
\end{array}\right.} \\
\left(j \omega L_{\mathrm{VAr}}+R_{\mathrm{VAr}}\right) \\
\left(j \omega L_{\mathrm{VAr}}+R_{\mathrm{VAr}}+j \omega L_{\mathrm{TR}}+R_{\mathrm{TR}}\right)
\end{array}\right]\left[\begin{array}{c}
I_{\mathrm{A} 1} \\
I_{\mathrm{A} 2} \\
I_{\mathrm{TR}}
\end{array}\right]=\left[\begin{array}{c}
V_{\mathrm{S}} \\
0 \\
V_{\mathrm{TR}}
\end{array}\right]
$$

For the line to be modeled in MATLAB Simulink, the formed equations are created in matrix form as follows.

The third part of the line is the part between the $\mathrm{A} 2$ point and the transformer, and the third part of the mathematical model is found for the simulation model. The equation is equal to transformer voltage $\left(V_{\mathrm{TR}}\right)$ because the voltage of the

$V_{\mathrm{TR}}=I_{\mathrm{A} 2}\left(j \omega L_{\mathrm{VAr}}+R_{\mathrm{VAr}}\right)+$

$+I_{\mathrm{TR}}\left(j \omega L_{\mathrm{TR}}+R_{\mathrm{TR}}+j \omega L_{\mathrm{TR}}+R_{\mathrm{TR}}\right)$

$V_{\mathrm{TR}}=I_{\mathrm{TR}}\left(Z_{\mathrm{VAr}}+Z_{\mathrm{TR}}\right)+I_{\mathrm{A} 2}\left(Z_{\mathrm{VAr}}\right)$

$$
\left[\begin{array}{ccc}
\left(Z_{\mathrm{S}}+Z_{\mathrm{VAr}}+R_{\mathrm{L}}\right) & \left(Z_{\mathrm{VAr}}\right) & 0 \\
-\left(Z_{\mathrm{VAr}}\right) & \left(2 Z_{\mathrm{VAr}}+2 Z_{\mathrm{w}}+\frac{1}{j \omega C_{\mathrm{g}}}\right) & \left(Z_{\mathrm{VAr}}\right) \\
0 & \left(Z_{\mathrm{VAr}}\right) & \left(Z_{\mathrm{VAr}}+Z_{\mathrm{TR}}\right)
\end{array}\right]\left[\begin{array}{c}
I_{\mathrm{A} 1} \\
I_{\mathrm{A} 2} \\
I_{\mathrm{TR}}
\end{array}\right]=\left[\begin{array}{c}
V_{\mathrm{S}} \\
0 \\
V_{\mathrm{TR}}
\end{array}\right]
$$

\section{SIMULATION OF THE LINE TO BE COMPENSATED}

In Fig. 2, the line fed by the solar energy is created in MATLAB Simulink after the mathematical equations are formed. The simulation of the $240 \mathrm{~km}$ line is carried out by using the switching frequencies of 5 microseconds. When a 6-cycle fault is applied with a fault switch at the A2 node, a transient performance of this circuit is tested. Therefore, the fault is simulated by a breaker block. The times of switching can be defined in the breaker block menu.

For a better understanding of the transient behavior of this series-compensating network, a frequency analysis is realized by measuring the impedance at the $\mathrm{A} 2$ node. After this measurement is executed by a connecting impedance measurement block, the result is shown in Fig. 3(a). Fig. 3(b) shows the shape of alternating voltage and harmonic distortion.

For the simulation model in Fig. $2, R_{\mathrm{L}}$ is $2 \Omega$; $\mathrm{Q}$ is $55 \mathrm{VAr}$ for $Z_{\mathrm{VAr}} . R, L, C$ values for the impedance of the line $\left(Z_{\mathrm{w}}\right)$ are given respectively as $1.331 \mathrm{ohm}, 104 \times 10^{-3} \mathrm{H}, C=1610 \times 10^{-9}$ $\mathrm{F}$ on a frequency of $80 \mathrm{~Hz} . C_{\mathrm{g}}=67.6 \times 10^{-6} \mathrm{~F} . R_{\mathrm{S}}=180.1 \Omega$, $L_{\mathrm{S}}=0.026525 \mathrm{H}, C_{\mathrm{S}}=117.84 \times 10^{-6}$. The nominal power and frequency are respectively $330.10^{6} / 3 \mathrm{VA}, 80 \mathrm{~Hz}$. The transformer for the winding1 parameters are $V_{\mathrm{TR} 1}, L_{\mathrm{TR} 1}, R_{\mathrm{TR} 1}$ $=360000 / 3^{1 / 3}, 0.001 \Omega, 0.15 \mathrm{H}$. The transformers for the winding1 parameters are $V_{\mathrm{TR} 2}, L_{\mathrm{TR} 2}, R_{\mathrm{TR} 2}=180000 / 3^{1 / 3}$, $0.001 \Omega$. For a better understanding of the transient behavior of this series-compensating network, a frequency analysis is realized by measuring the impedance at the $\mathrm{A} 2$ node. After this measurement is executed by the connecting impedance measurement block, the result is shown in Fig. 3. Fig. 3 (a) 
shows the shape of alternating voltage, while Fig. 3(b) shows harmonic distortion. Since the distortion of the two-cycle alternating voltage is measured, the number of harmonics is larger than that of a single cycle. The harmonic distortion occurring during the conversion of the DC voltage obtained from the solar power plant to the alternating voltage is $2.76 \%$.
This power transmission line is a single-phase transmission line and because the generated alternating voltage is $80 \mathrm{~Hz}$ in the inverter output, the main harmonic takes the greatest value at $80 \mathrm{~Hz}$. The renewable direct current voltage from the solar power plant is converted by a 35-level inverter as in Fig. 4.

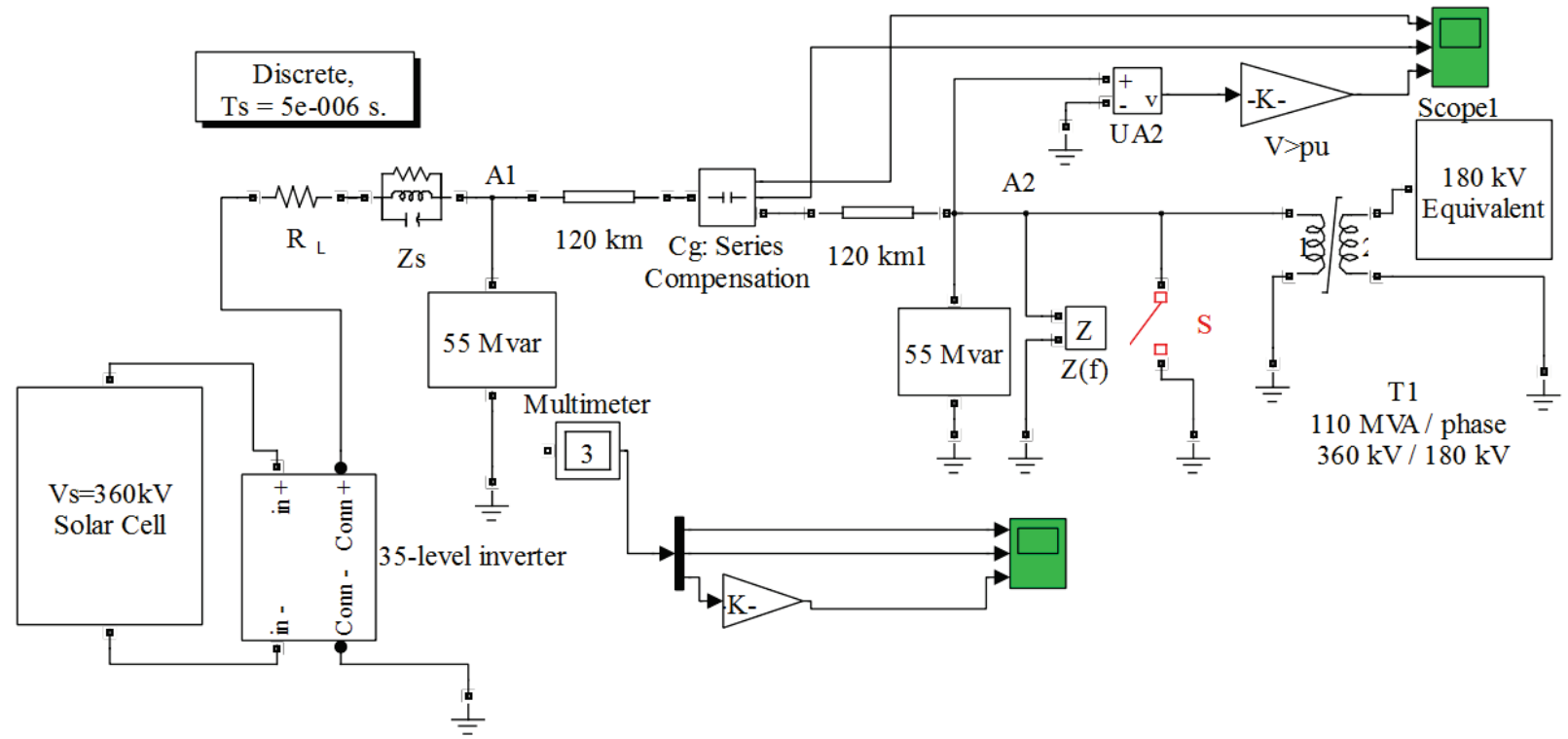

Figure 2 Line fed by solar energy modeled in MATLAB Simulink
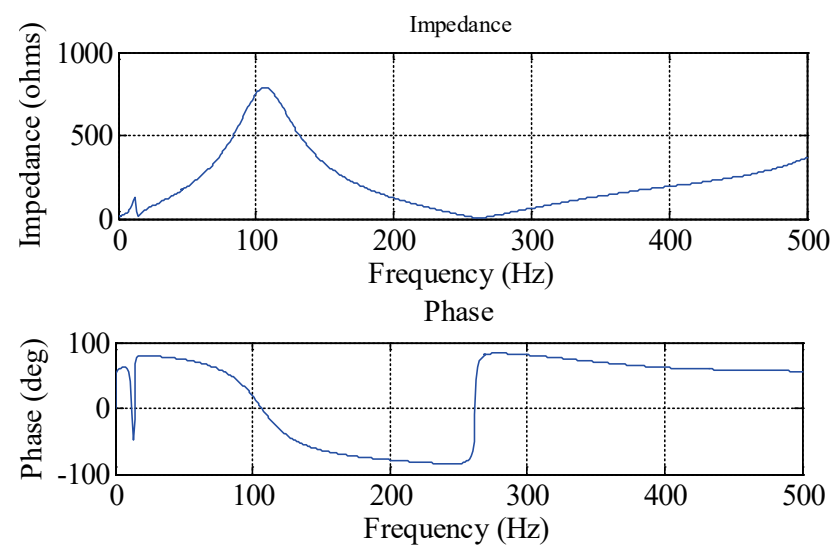

a)
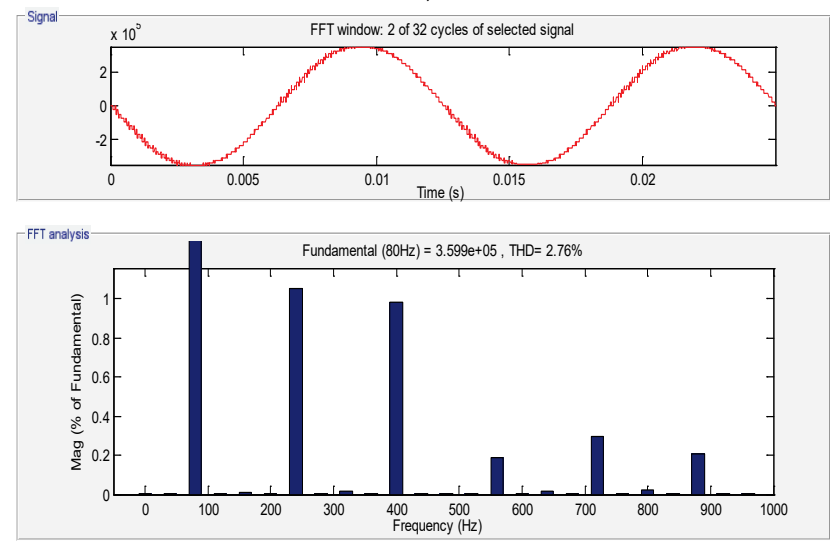

b)

Figure 3 a) Frequency Analysis for alternating voltage at $80 \mathrm{~Hz}$, b) harmonic distortion of alternating voltage converted from a solar power plant
The renewable direct current voltage from solar batteries is converted by a 35-level inverter as in Fig. 4.

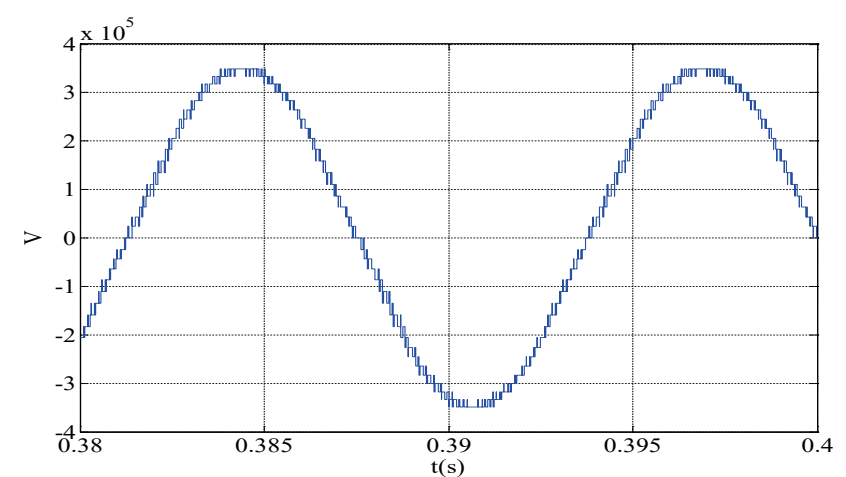

a)

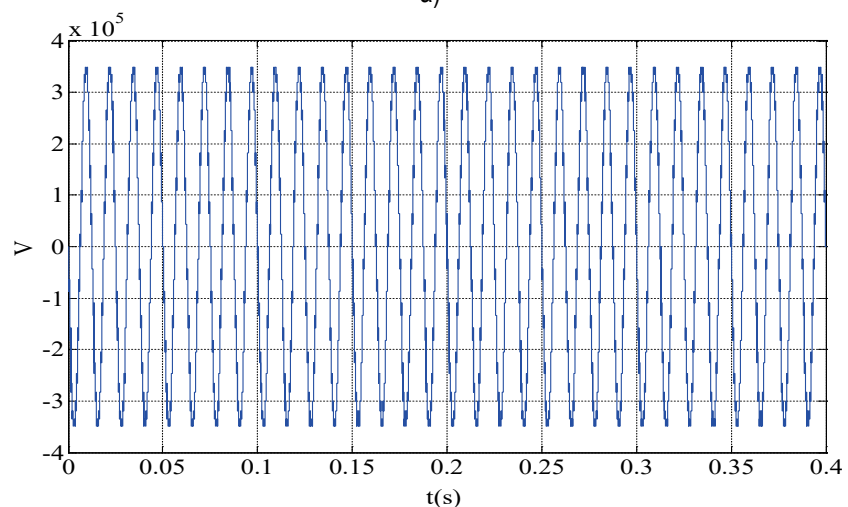

b)

Figure 4 Renewable voltage converted by a 35-level inverter a) short section b) long section 
To get the results in Fig. 3, the circuit modeled in MATLAB Simulink is run for $0.4 \mathrm{~s}$. After clicking on the discrete button on the simulation page, the converted voltage and harmonic distortion are obtained by selecting the FFT button from the opened page. Impedance and frequency are clicked and the phase angle and impedance values are taken for a resonance moment as in Fig. 3. According to the impedance curves for the converted voltage from a solar power plant at $80 \mathrm{~Hz}$, parallel resonances correspond to the $10 \mathrm{~Hz}$ and $110 \mathrm{~Hz}$ modes.

The $10 \mathrm{~Hz}$ mode is due to the parallel resonance of series capacitance and the shunt reactance of the line. The $110 \mathrm{~Hz}$ mode occurs due to the resonance effect of the shunt line capacitance and the series reactance of the transmission system. By using these two modes, faults can be eliminated. When a conversion of voltage obtained from renewable energy sources is made by a switching inverter circuit, it is difficult that the voltage obtained is close to the sinus. The converted voltage at a sinus shape can be achieved with 35 level inverters in this application. The peak value of $360 \mathrm{kV}$ for a converted wave appears in Fig. 4. The fault current, imaginary transformer current and transformer flux are shown in Fig. 5 when the $\mathrm{S}$ switch is turned on and off.
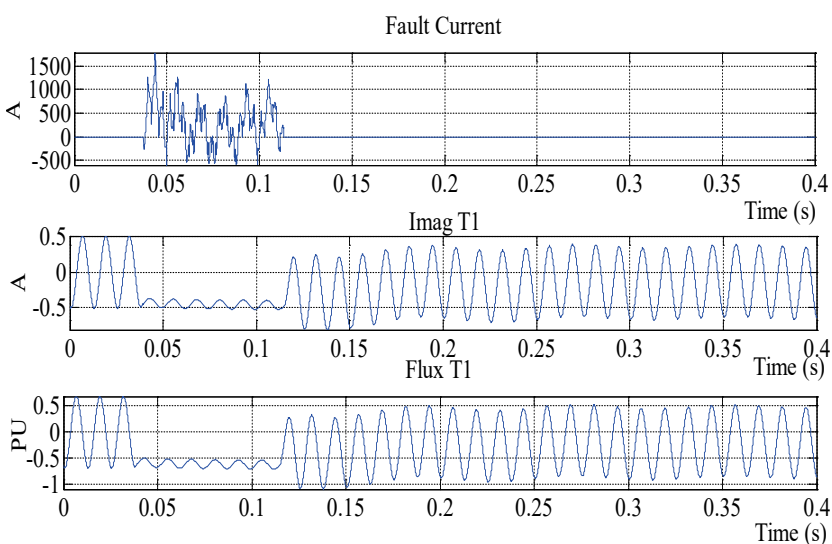

Figure 5 Fault current, imaginary transformer current and transformer flux

When the fault is generated, the transformer flux and the imaginary current decrease by $80 \%$ and the fault current reach $800 \mathrm{~A}$. After the fault, ImagT1 is $0.5 \mathrm{~A}$ while FluxT1 is $0.5 \mathrm{pu}$. After the simulation of the line for the alternating voltage at $80 \mathrm{~Hz}$, the capacitor voltage, the current of the MOW and the current of the node A2 appear as shown in Fig. 6.

Capacitor voltage reaches a very high value such as 40 $\mathrm{kV}$ and the current of the $\mathrm{A} 2$ node is zero from $0.04 \mathrm{~s}$ to1.1s, which is fault duration. After eliminating the fault, capacitor voltage decreases rapidly and becomes stable. After the fault, the flux is at the A2 point as $0.8 \mathrm{pu}$. After the line is performed for alternating voltage at the $80 \mathrm{~Hz}$, parallel reactive powers are changed to $40 \mathrm{MVar}$ to perform series compensation at $50 \mathrm{~Hz}$. The impedance-frequency response with respect to the A2 point is shown in Fig. 7 when the line is fed with the converted voltage from a solar power plant at $50 \mathrm{~Hz}$.
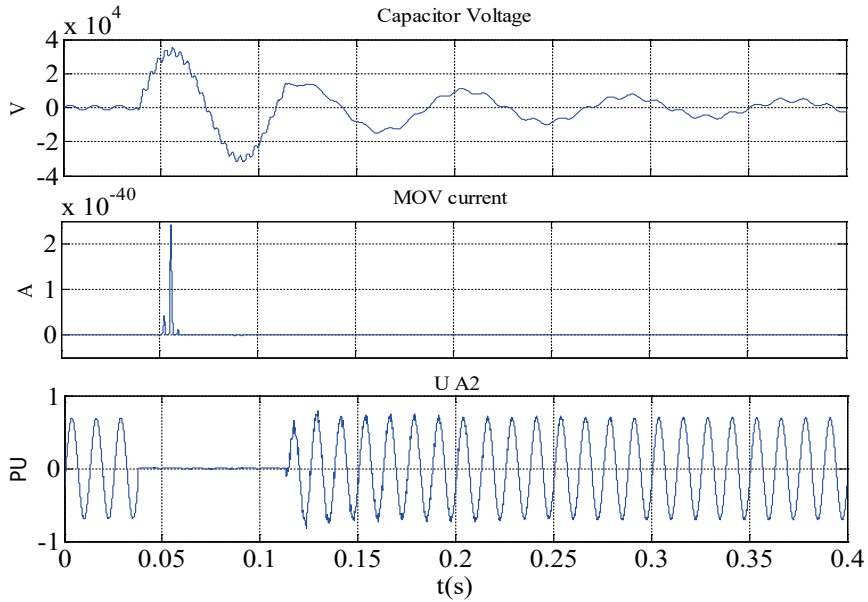

Figure 6 Capacitor voltage, the current of the MOW and the flux of the A2 node at $80 \mathrm{~Hz}$

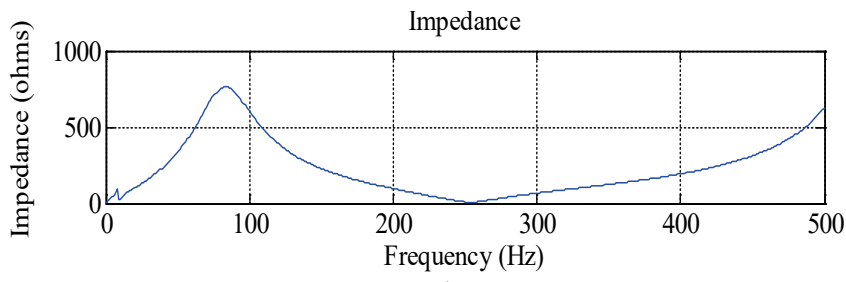

Phase

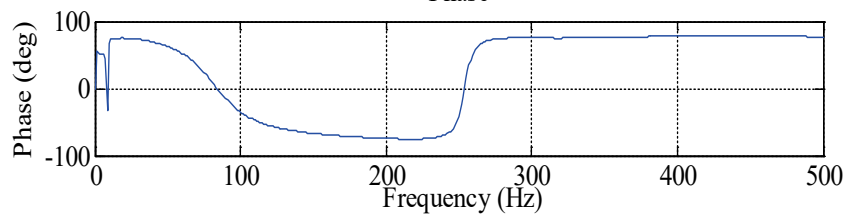

Figure 7a) Frequency Analysis for alternating voltage at $50 \mathrm{~Hz}$
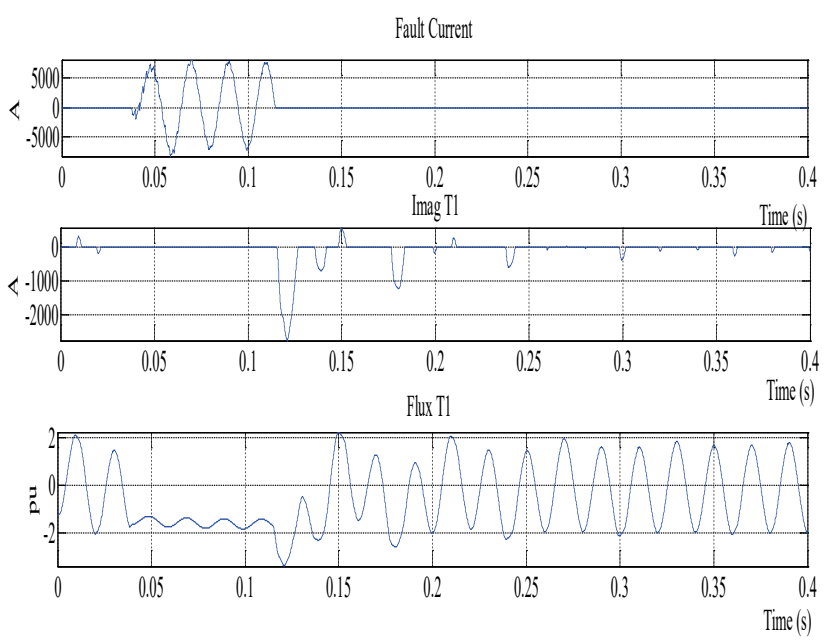

Figure 8 Fault current, ImagT1, and FluxT1

According to the impedance curves for the converted voltage from a solar power plant at $50 \mathrm{~Hz}$, parallel resonances correspond to the $5 \mathrm{~Hz}$ and $85 \mathrm{~Hz}$ modes. The $5 \mathrm{~Hz}$ mode is due to a parallel resonance of the series capacitance and the shunt reactance of the line. The $85 \mathrm{~Hz}$ mode occurs due to the resonance effect of the shunt line capacitance and the series reactance of the transmission system. By using these two modes, faults can be eliminated. 
After the simulation of the line for alternating voltage at $50 \mathrm{~Hz}$, the capacitor voltage, the current of the MOW and the flux of the A2 node appear in Fig. 9, while Fig. 8 demonstrate the fault current, ImagT1, and FluxT1.

Fig. 8 shows the fault current, ImagT1, and FluxT1 for 50 Hz.

Fig. 9 demonstrates capacitor voltage, the current of the MOW and the flux of the A2 node for alternating voltage at $50 \mathrm{~Hz}$.
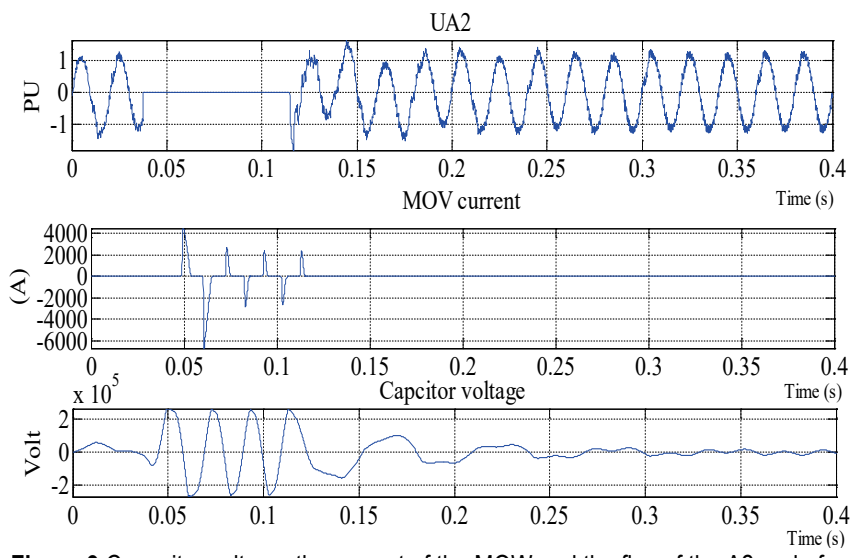

Figure 9 Capacitor voltage, the current of the MOW and the flux of the A2 node for alternating voltage at $50 \mathrm{~Hz}$

At the frequency of $50 \mathrm{~Hz}$, the error current in Fig. 8 is $8000 \mathrm{~A}$, which is why ImagT1 and FluxT1 become zero. In Fig. 9, after the capacitor voltage reaches $2200 \mathrm{~V}$ during the fault, the flux of the UA2 point is 1 pu at 0.13 seconds.

In different frequencies, some variables of the series compensated line are given in Tab. 1.

Table1 Values of the line at $80 \mathrm{~Hz}$ and $50 \mathrm{~Hz}$

\begin{tabular}{|c|c|c|c|c|c|}
\hline & $\begin{array}{c}\text { Flux of } \\
\mathrm{A} 2\end{array}$ & $\mathrm{Q}$ & $\begin{array}{c}\text { Resonance } \\
\text { frequencies }\end{array}$ & $\begin{array}{c}\text { Capacitor } \\
\text { voltages }\end{array}$ & FluxT1 \\
\hline $80 \mathrm{~Hz}$ & $0.8 \mathrm{pu}$ & $55 \mathrm{MVAr}$ & $10 / 115 \mathrm{~Hz}$ & $40 \mathrm{kV}$ & $0.5 \mathrm{pu}$ \\
\hline $50 \mathrm{HZ}$ & $1.2 \mathrm{pu}$ & $40 \mathrm{MVAr}$ & $5 / 85 \mathrm{~Hz}$ & $24 \mathrm{kV}$ & $2 \mathrm{pu}$ \\
\hline
\end{tabular}
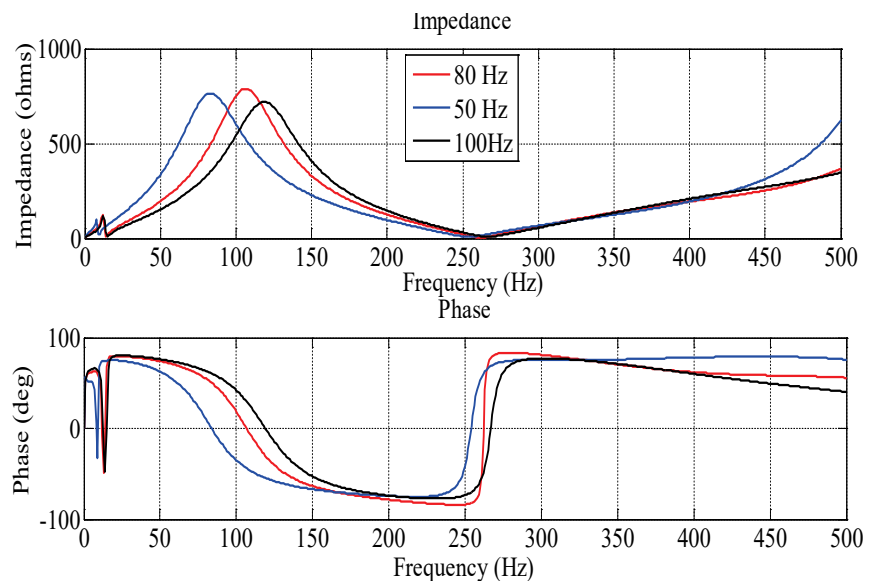

Figure 10 Frequency response of the power line at the $50 \mathrm{~Hz}, 80 \mathrm{~Hz}$ and $100 \mathrm{~Hz}$ frequencies

Capacitor voltage is at a very high value such as $25 \mathrm{kV}$ and the flux of the A2 node is zero from $0.04 \mathrm{~s}$ to $1.1 \mathrm{~s}$, which is fault duration. After eliminating the fault, capacitor voltage decreases rapidly and becomes stable. After the fault, the current flows at the $\mathrm{A} 2$ point as $1.2 \mathrm{pu}$.

The flux of the A2 point rises from $0.8 \mathrm{pu}$ to $1.2 \mathrm{pu}$ due to the frequency dropping from $80 \mathrm{~Hz}$ to $5 \mathrm{~Hz}$ and the reactive power dropping from $55 \mathrm{MVAr}$ to $40 \mathrm{MVAr}$. In this way, the power line powered by solar energy at different frequencies is successfully serial-compensated.

At $50 \mathrm{~Hz}, 80 \mathrm{~Hz}$ and $100 \mathrm{~Hz}$ frequencies, the frequency response of the power line appears in Fig. 10.

When the frequency of the alternating voltage obtained from solar energy changes from a frequency of $50 \mathrm{~Hz}$ to 100 $\mathrm{Hz}$, the frequency response of the line is shifted from $85 \mathrm{~Hz}$ to $125 \mathrm{~Hz}$ due to the resonance effect of the line reactance and the parallel line capacitance of the transmission line. The impedance values at these frequencies vary from $750 \Omega$ to $800 \Omega$. Therefore, while the line is fed by the voltages at different frequencies obtained from solar energy, the condition of the line can be observed. In the application of a renewable energy source with switching inverters, since the mains frequency can vary from country to country, the power line has been tried in the frequency range of $50-100 \mathrm{~Hz}$. Furthermore, the energy was then successfully transmitted with the eliminated faults through the power line.

\section{CONCLUSION}

In this article, when the fault was occurring on the transmission line of $240 \mathrm{~km}$ while obtaining voltage at a different frequency with the 35-level inverter from solar energy, the response of the power line at the case of compensation of this fault was investigated in the MATLAB Simulink. So, mathematical models of the power line were created and then the simulation model was tested in MATLAB Simulink.

According to the simulation results for the converted voltage from a solar power plant at $80 \mathrm{~Hz}$, parallel resonances corresponded to the $10 \mathrm{~Hz}$ and $110 \mathrm{~Hz}$ modes. The $10 \mathrm{~Hz}$ mode was due to a parallel resonance of the series capacitance and the shunt reactance of the line. The $110 \mathrm{~Hz}$ mode occurred due to the resonance effect of the shunt line capacitance and the series reactance of the transmission system. It was seen that the fault current reached 1750 amperes when the fault at the line was created with the switch. The capacitor voltage was $40 \mathrm{kV}$ when the current of the A2 point was zero from $0.04 \mathrm{~s}$ to1.1 s, at which the fault occurred. According to the simulation results for the converted voltage from a solar power plant at $50 \mathrm{~Hz}$, parallel resonances corresponded to the $5 \mathrm{~Hz}$ and $85 \mathrm{~Hz}$ modes. The $5 \mathrm{~Hz}$ mode was due to a parallel resonance of the series capacitance and the shunt reactance of the line. The $85 \mathrm{~Hz}$ mode occurred due to the resonance effect of the shunt line capacitance and the series reactance of the transmission system. The energy transmission on the compensated line continued to be balanced and smooth after the fault had been fixed. The harmonic distortion of the alternating voltage generated by the inverter on the power line was $2.78 \%$ and the acceptable value is below $5 \%$. Although it is a difficult, expensive and time-consuming process to work on long lines, this simulated model with MATLAB Simulink 
measures the response of a solar-powered line in a short time and at a low cost.

\section{REFERENCES}

[1] Millstein, D., Wiser, R., Bolinger, M., \& Barbose, G. (2017). The climate and air-quality benefits of wind and solar power in the United States. Nature Energy, 2(9), nenergy 2017134. https://doi.org/10.1038/nenergy.2017.134

[2] François, B., Zoccatelli, D., \& Borga, M. (2017). Assessing small hydro/solar power complementarity in ungauged mountainous areas: A crash test study for hydrological prediction methods. Energy, 127, 716-729. https://doi.org/10.1016/j.energy.2017.03.090

[3] Yang, Y., Zhong, W., Kiratipongvoot, S., Tan, S. C., \& Hui, S. R. (2017). Dynamic Improvement of Series-Series Compensated Wireless Power Transfer Systems Using Discrete Sliding Mode Control. IEEE Transactions on Power Electronics.

[4] Bogdan, A. V. \& Tropin, V. V. (2017, May). Analysis of transient start asynchronous motor series compensated reactive power. International Conference on Industrial Engineering, Applications and Manufacturing (ICIEAM 2017), IEEE, 1-4.

[5] Feng, H., Cai, T., Duan, S., Zhang, X., Hu, H., \& Niu, J. (2017). A Dual-Side Detuned Series-Series Compensated Resonant Converter for Wide Charging Region in Wireless Power Transfer System. IEEE Transactions on Industrial Electronics.

[6] Liu, J., Sun, Y., Li, Y., \& Fu, C. (2016). Theoretical harmonic analysis of cascaded H-bridge inverter under hybrid pulse width multilevel modulation. IET Power Electronics, 9(14), 2714-2722. https://doi.org/10.1049/iet-pel.2016.0163

[7] Xavier, L. S., Cupertino, A. F., de Resende, J. T., Mendes, V. F., \& Pereira, H. A. (2017). Adaptive current control strategy for harmonic compensation in single-phase solar inverters. Electric Power Systems Research, 142, 84-95. https://doi.org/10.1016/j.epsr.2016.08.040

[8] Saygin, A.; Aksoz, A.; Yilmaz, (2016). E. N. A different model of WECS connected to smart grid through matrix converter. Smart Grid Congress and Fair (ICSG2016), $4^{\text {th }}$ International IEEE, Istanbul, 1-5.

[9] Xavier, L. S., Cupertino, A. F., Mendes, V. F., \& Pereira, H. A. (2015, November). A novel adaptive current harmonic control strategy applied in multifunctional single-phase solar inverters. Power Electronics Conference and $1^{\text {st }}$ Southern Power Electronics Conference (COBEP/SPEC2015) IEEE $13^{\text {th }}$ Brazilian, 1-6.

[10] Li, R., Wang, W., Chen, Z., Jiang, J., \& Zhang, W. (2017). A Review of Optimal Planning Active Distribution System: Models, Methods, and Future Researches. Energies, 10(11), 1715. https://doi.org/10.3390/en10111715

[11] Liu, Y., Meliopoulos, S., Tai, N., Sun, L., \& Xie, B. (2017). Protection and Fault Locating Method of Series Compensated Lines by Wavelet Based Energy Traveling Wave. IEEE Power and Energy Society (PES) General Meeting.

[12] Can, E. (2017). Novel high multilevel inverters investigated on simulation. Electrical Engineering, 99(2), 633-638. https://doi.org/10.1007/s00202-016-0396-z

[13] Can, E. \& Sayan, H.H. (2016). PID and fuzzy controlling three phase asynchronous machine by low level DC source three phase inverter. Tehnički vjesnik, 23 (3), 753-760. https://doi.org/10.17559/TV-20150106105608

[14] Kerem, A., Aksoz, A., Saygin, A., \& Yilmaz, E. N. (2017). Smart grid integration of micro hybrid power system using 6switched 3-level inverter. Smart Grid and Cities Congress and
Fair (ICSG2017) $5^{\text {th }}$ International IEEE, Istanbul, 161-165. https://doi.org/10.1109/SGCF.2017.7947625

[15] Can, E. \& Sayan, H.H. (2016). SSPWM three phase inverter design and experimented on unbalanced loads. Tehnički vjesnik, 23 (5), 1239-1244. https://doi.org/10.17559/TV-20150730222021

[16] Sarwar, A., \& Asghar, M. S. (2011). Simulation and analysis of a multilevel converter topology for solar PV based gridconnected inverter. Smart Grid and Renewable Energy, 2(1), 56. https://doi.org/10.4236/sgre.2011.21007

[17] Yelpale, P. R., Jadhav, H. T., \& Chormale, C. (2017). New control strategy for grid integrated PV solar farm to operate as STATCOM. International Conference on Circuit, Power and Computing Technologies (ICCPCT2017), IEEE, 1-6.

[18] Sinu, K. J. \& Ranganathan, G. (2018). A PV FED Three Phase Switched Z-Source Multi Level Inverter for Induction Motor Drives. Indonesian Journal of Electrical Engineering and Computer Science, 9(1), 24-28. https://doi.org/10.11591/ijeecs.v9.i1.pp24-28

Author's contacts:

Erol CAN, Assist. Prof. Dr. School of Civil Aviation, Erzincan University, Aircraft Airframe Power Plant, Yanliz Bag Yerleşkesi, 24100 Erzincan, Turkey cn_e@hotmail.com 